\title{
Estimation of birth weight by measurement of fundal height and abdominal girth in parturients at term
}

\author{
F. Mortazavi ${ }^{1}$ and A. Akaberi ${ }^{2}$
}

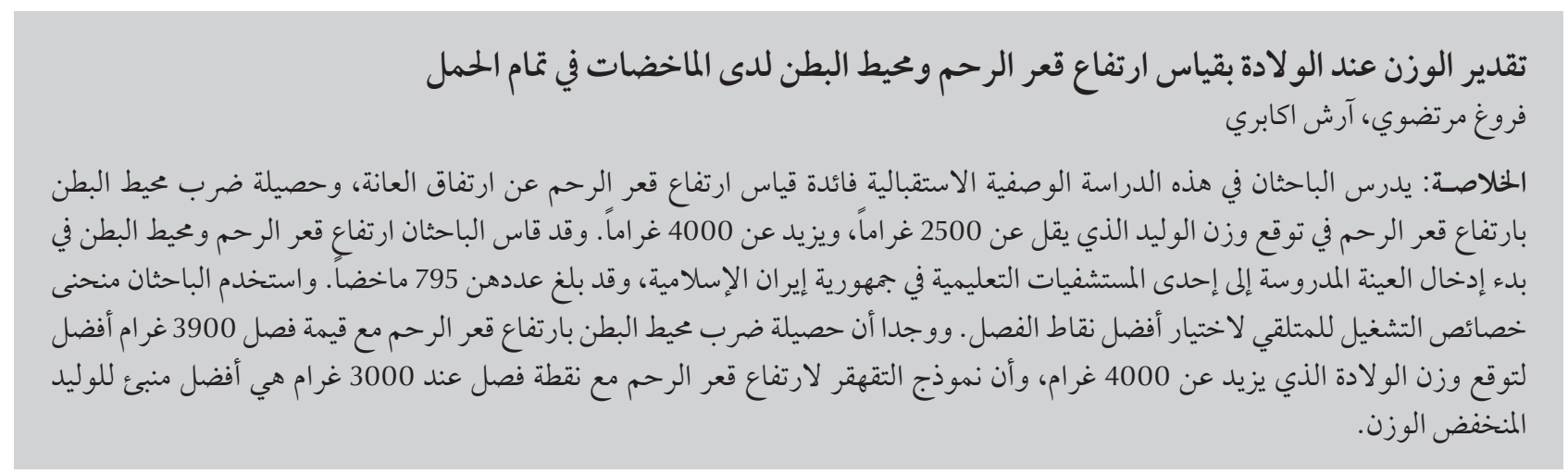

ABSTRACT In a prospective descriptive study, the usefulness of symphysis-fundal height and the product of abdominal girth and fundal height in predicting birth weight $<2500 \mathrm{~g}$ and $>4000 \mathrm{~g}$ were examined. Fundal height and abdominal girth were measured at the time of admission on a sample of 795 parturient women at a teaching hospital in the Islamic Republic of Iran. Receiver operating characteristics curve analysis was used to select the best cut-off points. The product of abdominal girth $\times$ fundal height with the cut-off at $3900 \mathrm{~g}$ performed better for predicting birth weight $>4000 \mathrm{~g}$, but for low birth weight, the regression model of fundal height with cut-off at $3000 \mathrm{~g}$ was a better predictor.

Estimation du poids de naissance par la mesure de la hauteur utérine et du tour de taille de parturientes à terme

RÉSUMÉ Une étude prospective descriptive a permis d'évaluer l'utilité de la mesure de la distance entre la symphyse pubienne et le fond utérin, et du produit du tour de taille par la hauteur utérine pour l'estimation des poids de naissance inférieurs à $2500 \mathrm{~g}$ et supérieurs à $4000 \mathrm{~g}$. La hauteur utérine et le tour de taille ont été mesurés sur un échantillon de 795 parturientes lors de leur admission dans un hôpital universitaire en République islamique d'Iran. L'analyse de la courbe ROC (pour Receiver Operating Characteristics) a été utilisée pour sélectionner les meilleures valeurs de seuil. Le produit du tour de taille par la hauteur utérine, avec une valeur de seuil de $3900 \mathrm{~g}$, a permis d'obtenir les meilleures estimations pour les poids de naissance supérieurs à $4000 \mathrm{~g}$. En revanche, pour les faibles poids de naissance, le modèle de régression de la hauteur utérine, avec valeur de seuil de $3000 \mathrm{~g}$, produisait de meilleures estimations.

${ }^{7}$ Department of Midwifery; ${ }^{2}$ Department of Health, Sabzevar Faculty of Medical Sciences, Sabzevar, Islamic Republic of Iran (Correspondence to F. Mortazavi:frmortazavi@yahoo.com).

Received: 15/02/08; accepted: 28/05/08 


\section{Introduction}

Precise estimation of birth weight (BW) is one of the most important measures at the beginning of labour. This is especially important in developing countries where many births occur at home or at birth centres without adequate facilities. In these circumstances diagnosis of macrosomic and light fetuses can result in timely referral of diagnosed cases to well-equipped hospitals.

There are 2 common methods of estimation of BW: sonographic evaluation and clinical palpation [1]. In developing countries, ultrasonography may be unavailable or may not be affordable by patients. Physician estimates of BW by palpation are as reliable as, or superior to, those made from ultrasonographic measurements of the fetus [2]. However, their accuracy depends on experience, which may be lacking in many obstetric care personnel in developing countries [1]. That is why measurement of fundal height (FH) using inexpensive and easily available non-elastic tapes has been recommended as a means of assessing $\mathrm{BW}$ in low-resource countries.

In some studies $\mathrm{BW}<2500 \mathrm{~g}$ and > $4000 \mathrm{~g}$ have been proposed as the cutoff points for predicting BW using $\mathrm{FH}$ measurement only $[1-6]$. Since the size of the fetus affects the abdominal girth (AG), a cut-off point for AG as a predictor of $\mathrm{BW}<2500 \mathrm{~g}$ has been calculated [7]. Still other studies have developed formulas based on the regression of BW on both $\mathrm{FH}$ and $\mathrm{AG}$ for predicting BW $[8,9]$. Dare et al. and Bothner et al. used the product of symphysis-FH and AG at the level of the umbilicus to estimate BW at term in utero, and their estimates correlated well with BW $[10,11]$. These 2 studies did not consider BW $<2500$ $\mathrm{g}$ and $>4000 \mathrm{~g}$. Shittu et al. compared the product of symphysis-FH and AG with sonographic estimation of BW and found that the product formula performed as well as sonographic estimation, except in $\mathrm{BW}<2500 \mathrm{~g}$ [12].
The aim of this study was to further examine and compare the performance of the product formula of $\mathrm{FH} \times \mathrm{AG}$ with that of the formula based on $\mathrm{FH}$ alone, to clarify whether taking an extra measurement, i.e. AG, improves the prediction of BW. Since studies have concluded that FH $[1,12-14]$, the product formula $[11,14]$ or formulas based on both FH and AG [8] are not powerful predictors of $\mathrm{BW}<2500 \mathrm{~g}$ or $>4000 \mathrm{~g}[1,8,11-14]$, we aimed to test the hypothesis that changing the cut-off points of the 2 formulas would be improved in the case of $\mathrm{BW}<2500$ g or $>4000 \mathrm{~g}$.

\section{Methods}

A prospective descriptive study was undertaken from 1 May to 1 August 2003 on 795 consecutive parturient women hospitalized at Mobini teaching and maternity hospital affiliated to Sabzevar Faculty of Medical Sciences, Islamic Republic of Iran, which is the only maternity hospital in this region providing standard maternity services to urban and rural women. The purpose of the original study was to estimate gestational age by measurement of $\mathrm{FH}$ and $A G$ in parturient women at term [13]. For this paper we reanalysed the data collected to estimate BW by the product formula.

\section{Sample}

Based on receiver operating characteristics (ROC) curve power analysis, the sample sizes required for achieving $80 \%$ power to detect a difference of 0.25 between the area under the ROC curve of 0.5 , using a significance level of 0.05 , was 11 for the positive group $(<2500 \mathrm{~g})$ and 500 from the negative group $(\geq 2500 \mathrm{~g})$. Also the sample sizes required for achieving $80 \%$ power to detect a difference of 0.3 between the area under the ROC curve of 0.5 , using a significance level of 0.05 , was 7 from the positive group $(>4000 \mathrm{~g})$ and 500 from the negative group $(\leq 4000 \mathrm{~g})[15,16]$. The differences of 0.25 and 0.30 were obtained by analysing the ROC curves, and the specified sample sizes were the maximum required for analysing the power of each formula. The size of the sample in the present study in each BW group was larger than the specified maximum required sample size.

The inclusion criteria were: alive, single and term fetuses with longitudinal lie. The exclusion criteria were: documented severe fetal congenital anomalies; preterm labour; presence of a thick deposited layer of fat at the lower abdomen; maternal weight $>91$ $\mathrm{kg}$; and clinical or ultrasonic evidence of uterine fibroids, oligohydramnios or polyhydramnios.

\section{Data collection}

The data were obtained by interview and by means of clinical assessment. The background characteristics of women were obtained by interview. Vaginal examination was carried out to determine the fetal station. As soon as a woman meeting the above criteria was admitted for vaginal or abdominal delivery, symphysis-FH and AG at the level of umbilicus were measured.

FHwas measured using a non-elastic tape from the highest point on the uterine fundus to the midpoint of the upper border of the symphysis pubis. The thumb was used to hold the tape while attempting to reach the upper border of the symphysis pubis. Measurement was made 3 times using the tape reverse-side up to avoid any bias. The mean of the 3 readings was then obtained to the nearest centimetre. The same precautions for preventing bias were made in the case of AG. Abdominal measurements were taken in the supine position with little flexion of legs, after emptying the bladder and during uterine relaxation periods. All the measurements were taken by 2 members of the research team who had been trained for the task. Informed written consent was obtained from all the women. 
To test the intra-rater reliability of trained observers, we asked them to take FH and AG measurements in 30 parturients. The mean difference for $\mathrm{AG}$ and $\mathrm{FH}$ measurements between 2 trained observers was $1.35 \mathrm{~mm}$ and $1.52 \mathrm{~mm}$ respectively. Also $98.0 \%$ of AG measurement differences and $97.2 \%$ of FH measurement differences were between $\pm 10 \mathrm{~mm}$ comparing the 2 observers. To further examine the intrarater reliability we used Bland-Altman scatter plots. The differences between the trained observers' measurements were plotted against the mean of the observers' measurements. Intra-rater scatter plots demonstrated that $96 \%$ of all AG and $92 \%$ of all FH measurement differences were within 2 standard deviations (SD) of acceptable levels of agreement.

The actual BW of the baby was measured in grams to the nearest $50 \mathrm{~g}$ by the midwife on duty within an hour of delivery using a weighing scale. The midwives who weighed the babies after birth were blind to the intrapartum estimates of BW.

\section{Birth weight estimates}

The 1st formula for estimating BW was the method of Dare et al. as the product of symphysis-FH and AG at the level of the umbilicus measured in $\mathrm{cm}[17]$ : $\mathrm{BW}=\mathrm{FH} \times$ abdominal girth.

The 2 nd formula for estimating BW was obtained by regression of BW on FH using sample data from the original study [13]: BW $=(\mathrm{FH} \times 87)+515$.

\section{Data analysis}

To predict $\mathrm{BW}<2500 \mathrm{~g}$ and $>4000 \mathrm{~g}$, the ROC curve was used to select cut-off points with the best sensitivity and specificity. Levels of significance in this study were $P<0.05$. The data were analysed using Pearson correlation coefficient, $t$ test, covariance analysis and ROC curve, using SPSS software, version 15.

\section{Results}

The studygroup consisted of 795 women, 442 (55.6\%) of whom were primiparous and 353 multiparous. The mean and standard deviation (SD) age and weight of the women were 25.0 (SD 5.28) years and 69.6 (SD 10.8) kg respectively.

The mean FH was 34.6 (SD 3.1) $\mathrm{cm}$, range $24-47 \mathrm{~cm}$, and for AG was $99.2(\mathrm{SD} 8.7) \mathrm{cm}$, range $75-124 \mathrm{~cm}$. The mean product of $\mathrm{FH} \times \mathrm{AG}$ was $3440($ SD 540$) \mathrm{cm}$, range $2184-5640$ $\mathrm{cm}$. All the mean values were higher in multiparous women than in primiparous women $(P<0.001)$ (Table 1$)$.

In $173(21.8 \%)$ of the cases engagement had already occurred at the time of admission. Covariance analysis, adjusted for age and weight of the woman, revealed significant differences in the mean value of FH between the 173 women presenting with the fetus part-engaged and the 622 with the fetus unengaged $[33.5(\mathrm{SD} 3.1) \mathrm{cm}$ versus $34.8($ SD 3.0) $(P<0.001)]$.

The mean actual BW of the infants was 3212 (SD 421) g, range 1600-4450 g. There were 27 (3.4\%) newborns with BW $>4000 \mathrm{~g}$ and 27 (3.4\%) with BW $<2500 \mathrm{~g}$.

All the correlation coefficients between the measured parameters for both the primiparous and multiparous group were significantly different from zero $(P$ $<0.001)$. The correlation coefficients between maternal indicators and BW were higher in the primiparous than in multiparous women. The correlation between $\mathrm{FH}$ and $\mathrm{BW}$ was stronger than the correlation between the product of $\mathrm{FH} \times \mathrm{AG}$ and $\mathrm{BW}$ ( 0.58 versus 0.56 ) (Table 2).

The best cut-off points of BW for detecting $\mathrm{BW}<2500 \mathrm{~g}$ and $>4000 \mathrm{~g}$ were determined for each formula using ROC curves. The cut-off point for

\begin{tabular}{|c|c|c|c|}
\hline \multirow[t]{2}{*}{ Parameter } & $\begin{array}{l}\text { Primiparous women } \\
\qquad(n=442)\end{array}$ & $\begin{array}{l}\text { Multiparous women } \\
\qquad(n=353)\end{array}$ & $\begin{array}{l}\text { All women } \\
(n=795)\end{array}$ \\
\hline & Mean (SD) & Mean (SD) & Mean (SD) \\
\hline \multicolumn{4}{|l|}{ Mothers } \\
\hline Weight (kg) & $68.0(10.0)$ & $71.6(10.0)$ & $69.6(10.0)$ \\
\hline Fundal height $(\mathrm{cm})$ & $34.2(3.1)$ & $35.0(3.1)$ & $34.6(3.1)$ \\
\hline Abdominal girth $(\mathrm{cm})$ & $97.3(8.4)$ & $101.6(8.3)$ & $99.2(8.7)$ \\
\hline \multicolumn{4}{|l|}{ Infants } \\
\hline $\begin{array}{l}\text { Estimated birth weight (by fundal } \\
\text { height } \times \text { abdominal girth) }(\mathrm{g})\end{array}$ & $3331(522)$ & $3575(533)$ & $3440(540)$ \\
\hline $\begin{array}{l}\text { Estimated birth weight (by } \\
\text { regression model of birth weight } \\
\text { on fundal height }^{\mathrm{a}} \text { (g) }\end{array}$ & 3487 (269) & $3563(271)$ & $3520(272)$ \\
\hline Actual birth weight (g) & $3153(421)$ & $3288(410)$ & $3213(421)$ \\
\hline
\end{tabular}

${ }^{a}$ Estimated birth weight $=($ fundal height $\times 87)+515$.

$S D=$ standard deviation . 


\begin{tabular}{lccc}
\hline Table 2 Distribution of correlation coefficients between measured parameters by parity & \\
\hline Parameter & $\begin{array}{c}\text { Primiparous women } \\
(\boldsymbol{n}=\mathbf{4 4 2})\end{array}$ & $\begin{array}{c}\text { Multiparous women } \\
(\boldsymbol{n}=353)\end{array}$ & $\begin{array}{c}\text { All women } \\
(\boldsymbol{n}=\mathbf{7 9 5})\end{array}$ \\
Fundal height & 0.60 & 0.54 & 0.58 \\
Abdominal girth & 0.44 & 0.29 & 0.40 \\
Fundal height $\times$ abdominal girth & 0.59 & 0.48 & 0.56 \\
\hline
\end{tabular}

All $P$ values $<0.001$

predicting BW > $4000 \mathrm{~g}$ was $3900 \mathrm{~g}$ based on the $\mathrm{FH} \times \mathrm{AG}$ formula and $3450 \mathrm{~g}$ based on the regression model of BW on FH. The sensitivity and specificity of the obtained cut-off point for the $\mathrm{FH} \times \mathrm{AG}$ formula for the detection of BW > $4000 \mathrm{~g}$ were $81.3 \%$ (95\% CI: $80.2 \%-82.4 \%$ ) and $82.2 \%$ (95\% CI: $81.2 \%-83.2 \%)$ respectively. The corresponding values for the regression model of BW on FH were $75.0 \%$ (95\% CI: $73.7 \%-76.3 \%)$ and $85.4 \%$ (95\% CI: 84.5\%-86.3\%) (Table 3).

To predict $\mathrm{BW}<2500 \mathrm{~g}$, a single cut-off point equal to $3000 \mathrm{~g}$ was obtained for both formulas. Sensitivity and specificity of the obtained cut-off point for the FH $\times$ AG formula were $70.4 \%$ (95\% CI: $68.9 \%-71.8 \%$ ) and $79.9 \%$ (95\% CI: 78.8\%-81.0\%) respectively and for the regression model of BW on FH formula, the corresponding values were $77.8 \%$ (95\% CI: 76.6\%-79.0\%) and $85.5 \%$ (95\% CI: $84.6 \%-86.4 \%$ ) (Table 4). The cut-off points were selected on the basis that we considered a satisfactory level of sensitivity to be at least $70 \%$ and also sought a relatively high level of specificity.

\section{Discussion}

In this study, 2 estimators of birth weight, that is a regression model of $\mathrm{FH}$ and the product of $\mathrm{FH} \times \mathrm{AG}$ were evaluated and compared, with particular emphasis on BW $<2500 \mathrm{~g}$ and $>4000$ g. Our results showed that the mean values for weight of parturient, BW, FH and AG were higher in multiparous than in primiparous parturients. This is due to the fact that multiparous women generally tended to be fatter; this leads to higher BW which in turn results in higher values of $\mathrm{FH}$ and $\mathrm{AG}$. In other studies this correlation coefficient was as follows: 0.56 [11], 0.91 [1], 0.59 [3], $0.74[4], 0.87[6], 0.74[9]$ and $0.72[5]$. The correlation between the product of $\mathrm{FH} \times \mathrm{AG}$ and BW was 0.56 in our study. In other studies it was 0.74 and 0.57 respectively $[10,14]$.

As stated above, by using the ROC curve we were able to find cut-off points of BW for each formula in which they could predict $\mathrm{BW}<2500 \mathrm{~g}$ and $>4000$ $\mathrm{g}$ with maximum accuracy. The results indicate that using the product of $\mathrm{FH}$ $\times \mathrm{AG}$ the cut-off point $3900 \mathrm{~g}$ was a better estimator of high BW $(>4000 \mathrm{~g})$ than the regression model of $\mathrm{FH}$ at the cut-off point $3450 \mathrm{~g}$, and the regression model of FH at cut-off point $3000 \mathrm{~g}$ was a stronger predictor of low BW (< $2500 \mathrm{~g}$ ) than the $\mathrm{FH} \times \mathrm{AG}$ formula.

\begin{tabular}{|c|c|c|c|c|}
\hline Formula & $\begin{array}{l}\text { Sensitivity } \\
\%(\mathrm{Cl})\end{array}$ & $\begin{array}{l}\text { Specificity } \\
\%(\mathrm{Cl})\end{array}$ & $\begin{array}{l}\text { Positive predictive value } \\
\qquad \%(\mathrm{Cl})\end{array}$ & $\begin{array}{c}\text { Negative predictive value } \\
\qquad \%(\mathrm{Cl})\end{array}$ \\
\hline $\begin{array}{l}\text { Fundal height } \times \text { abdominal } \\
\text { girth }^{\mathrm{a}}\end{array}$ & $81.3(80.2-82.4)$ & $82.2(81.2-83.2)$ & 99.5 (99.5-99.5) & $86.0(81.0-91.0)$ \\
\hline $\begin{array}{l}\text { Regression model of birth } \\
\text { weight on fundal height } \mathrm{t}^{\mathrm{b}}\end{array}$ & $75.0(73.7-76.3)$ & $85.4(84.5-86.3)$ & 99.4 (99.4-99.4) & $95.0(89.0-100.0)$ \\
\hline
\end{tabular}

${ }^{a}$ Cut-off point $=3900 \mathrm{~g} ;{ }^{b} \mathrm{Cut}$-off point $=3450 \mathrm{~g}$.

$\mathrm{Cl}=$ confidence interval.

\begin{tabular}{|c|c|c|c|c|}
\hline Formula & $\begin{array}{c}\text { Sensitivity } \\
\qquad \%(\mathrm{Cl})\end{array}$ & $\begin{array}{c}\text { Specificity } \\
\text { \%(Cl) }\end{array}$ & $\begin{array}{c}\text { Positive predictive } \\
\text { value } \\
\%(\mathrm{Cl})\end{array}$ & $\begin{array}{c}\text { Negative predictive } \\
\text { value } \\
\%(\mathrm{Cl})\end{array}$ \\
\hline $\begin{array}{l}\text { Fundal height } \times \\
\text { abdominal girth }\end{array}$ & 70.4 (68.9-71.8) & 79.9 (78.8-81.0) & 98.7 (98.6-98.8) & $11.0(10.3-11.7)$ \\
\hline $\begin{array}{l}\text { Regression model of birth } \\
\text { weight on fundal height }\end{array}$ & 77.8 (76.6-79.0) & 85.5 (84.6-86.4) & 99.1 (99.0-99.2) & $18.9(17.8-20.0)$ \\
\hline
\end{tabular}

Cut-off point $=3000 \mathrm{~g}$.

$\mathrm{Cl}=$ confidence interval. 
A number of studies have found a strong correlation between $\mathrm{BW}$ and $\mathrm{FH}$, $\mathrm{BW}$ and $\mathrm{AG}$ and $\mathrm{BW}$ and the product formula $[1,3-14,18]$. However, most of them concluded that these indicators were not strong enough for the purpose of predicting $\mathrm{BW}<2500 \mathrm{~g}$ or $>$ $4000 \mathrm{~g}[1,3,5,7,8,14,17]$. Shittu et al, for example, concluded that although the product of $\mathrm{FH} \times \mathrm{AG}$ was as accurate as routine ultrasonographic estimation, it did not perform as satisfactorily in cases of low BW [12]. Berry et al. has concluded that neither clinical nor ultrasonographic parameters were satisfactory in identifying low-birth-weight fetuses [18]. Woo et al. reported that a formula based on the regression of $\mathrm{BW}$ on $\mathrm{FH}$ and $\mathrm{AG}[\mathrm{BW}=-1.515+(0.092$ $\times \mathrm{FH})+(0.016 \times \mathrm{AG})]$ was a powerful predictor of BW between 2500-3500 g but was not accurate enough in predicting $\mathrm{BW}<2500 \mathrm{~g}$ and $>3500 \mathrm{~g}$ [8]. They concluded that all the generated equations obtained from their sample similarly underestimated the BW in the larger babies and overestimated it in the smaller babies. Onah et al. also found a strong correlation (0.91) between FH and BW, but concluded that the regression model of FH was more useful in predicting BW between 2500-3999 g [1]. Kraiem's study, covering 400 cases of macrosomia, showed that the regression model of FH was not strong enough in predicting $\mathrm{BW}>4000 \mathrm{~g}$ [12].

As can be seen, our correlations were lower than, or at best equal to, the above mentioned studies. These weaker correlations and the fact that the cited studies, despite their reported higher correlations, produced unsatisfactory results in the case of predicting BW $<2500 \mathrm{~g}$ and $>4000 \mathrm{~g}$ would have led us to expect equally unsatisfactory or worse results in such cases too. In fact, applying the usual cut-off points (i.e. $2500 \mathrm{~g}$ and $4000 \mathrm{~g}$ ), we also obtained weak results which were in line with such expectations. However, we found that the shortcomings affecting these indicators could be overcome by using different cut-off points and employing the formula which performs better in predicting $\mathrm{BW}<2500 \mathrm{~g}$ and $>4000 \mathrm{~g}$.

Our results indicate that in the case of BW > $4000 \mathrm{~g}$, the $\mathrm{FH} \times \mathrm{AG}$ formula and a cut-off point of $3900 \mathrm{~g}$ performed better in predicting $\mathrm{BW}$, and in the case of $\mathrm{BW}<2500 \mathrm{~g}$, the regression of BW on FH formula and a cut-off point of $3000 \mathrm{~g}$ produced better predictions. Therefore we conclude that by selecting appropriate cut-off points specific to each community and employing the appropriate formula, it will be possible to utilize the 2 formulae for predicting $\mathrm{BW}<2500 \mathrm{~g}$ and $>4000 \mathrm{~g}$.

\section{Acknowledgements}

We acknowledge funding from Sabzevar Faculty of Medical Sciences.

\section{References}

1. Onah He, Ikeme AC, Nkwo PO. Correlation between intrapartum fundal height and birth weight. African journal of reproductive health, 2002, 6(2):23-9.

2. Coningham FG et al. Fetal growth disorders. In: Williams's obstetrics. Section 7. Common complications of pregnancy, 21st ed. New York, McGraw-Hill, 2001:759.

3. Labrecque M, Boulianne M. Estimation du poids de naissance par la mesure de la hauteur uterine chez la parturiente en Republique Federale Islamique des Comores [Estimation of birth weight by measuring the height of the uterus in the parturient women in the Islamic Federal Republic of Comoro Islands]. Revue d'épidémiologie et de santé publique, 1987, 35:378-85.

4. Mohanty C, Das BK, Mishra OP. Parturient fundal height as a predictor of low birth weight. Journal of tropical pediatrics, 1998, 44:222-4.

5. Aghababaii S, Nahidi F. The use of tricolor measuring tape as a predictor of birth weight. Journal of medical sciences Pakistan, 2005, 5(4):307-10.

6. Ghaemmaghami Fetal. Parturient fundal height and birth weight estimation. Archives of Iranian medicine, 2002, 5(2):80-3.

7. Mohanty C, Das BK, Mishra OP. Parturient abdominal circumference as a predictor of low birth weight. Journal of tropical pediatrics, 2000 46(6):363-4.

8. Woo JS et al. Estimation of fetal weight in utero from symphysis fundal height and abdominal girth measurements. Australian and New Zealand journal of obstetrics \& gynaecology, 1985, 25(4):268-71.

9. Hamudu NA. Shafiq M. Manji KP. Parturient symphysio-funda height and abdominal girth measurements to predict birth weight at Muhimbili Medical Centre, Dar es Salaam, Tanzania. Tanzania medical journal, 2004, 19(1):18-21.

10. Dare FO et al. The value of symphysio-fundal height/abdominal girth measurements in predicting fetal weight. International journal of gynecology and obstetrics, 1990, 31:243-8.

11. Bothner BK, Gulmezoglu AM, Hofmeyr GJ. Symphysis fundus height measurements during labour: a prospective, descriptive study. African journal of reproductive health, 2000, 4(1):48-55.

12. Shittu AS, Kuti O, Oriji EO. Comparison of clinical and ultrasonographic estimation of fetal weight. International journal of gynecology and obstetrics, 2003, 90(2):140-1.

13. Mortazavi F, Rakhshani MH. Estimation of gestational age by measurement of fundal height at the beginning of labor. Asrar Scientific Journal of Sabzevar Faculty of Medical Sciences, 2003, 10(4):39-44.

14. Kraiem J et al. Estimation clinique du poids foetal: interet dans la prediction de la macrosomie [Clinical fetal weight estimation and prediction of macrosomia]. La Tunisie médicale. 2004, 82(3):271-5.

15. Hanley JA, McNeill BJ. A method of comparing the areas under receiver operating characteristic curves derived from the same cases. Radiology, 1983, 148:839-48.

16. Obuchowski N, McClish D. Sample size determination for diagnostic accuracy studies involving binominal ROC curve indices. Statistics in medicine, 1997, 16:1529-42.

17. Shittu AS. Clinical versus sonographic estimation of foetal weight in southwest Nigeria. Journal of health, population and nutrition, 2007, 25(1):14-23.

18. Berry $\mathrm{M}$ et al. Foetal growth parameters--clinical versus ultrasonographic. Indian journal of pediatrics, 1992, 59(1):91-101. 